\title{
Multilayer PV-storage Microgrids Algorithm for the Dispatch of Distributed Network
}

\author{
Ping Yang ${ }^{1}$, Yu-jia Zhang ${ }^{1}$, Zhi-rong $\mathrm{Xu}^{1}$, Xu Yin ${ }^{1}$, Shao-xiong Zhou ${ }^{2}$, Jin-yong Lei ${ }^{3}$ \\ ${ }^{1}$ School of Electric Power, South China University of Technology, Guangzhou 510640, China. \\ ${ }^{2}$ Guangdong Intework Energy Technology Co, Ltd, Guangzhou, 511458, China. \\ ${ }^{3}$ Electric Power Research Institute, CSG, Guangzhou 510080, China.
}

\begin{abstract}
In recent years, due to the support of our country, PV-storage microgrid develops rapidly. However, the flexible network operation modes of PV-storage microgrid change flexibly and the operating characteristics with a large amout of sources is highly complicated. Based on the existing microgrid coordinate control methods, this paper proposes multilayer PV-storage microgrid algorithm for fitting dispatch of distributed network, which achieves maximum output of renewable energy when meeting the scheduling requirements of network, by building PV-storage microgrid type dynamic simulation system in a variety of conditions in PSCAD. Simulation results show that the heuristic algorithm proposed can achieve microgrid stable operation and satisfy the demands of the dispatch in distributed network.
\end{abstract}

\section{Introduction}

As severe environmental problems such as pollution and depletion of fossil fuels appeared, developing clean energy becomes more and more important. Solar energy, wind energy and other renewable energy power generation has achieved rapid development and wide application[1]. At the same time, as industrial civilization developing rapidly, problems and challenge toward EHV and long-distance power transmission appeared while the electricity demand increased and the size of traditional power grid expanded. Accordingly, microgrid has received attention from domestic and foreign researchers.

Microgrid is a small-scale power grid that can work connected to the utility grid or in island mode. The capacity of microgrid is from kilowatts to megawatts so the energy generated of the microgrid can be consumed locally[2,3]. Most of the power generators in microgrid, whose kinds of battery contain lithium batteries, flow batteries and other hybrid energy storage devices as power storage unit, includes photovoltaic generator, wind power generator, fuel cell, micro turbine, diesel generator and hydropower generator use renewable energy [3,4].

The most important characteristic of the microgrid is that it controls and dispatches the power sources and loads uniformly through the use of rational allocation of distributed power source and advanced control technology. It helps the independent generators and distribution system work as Cells[5]. Microgrid can either be connected with network or run independently. If we dispatch power source and the load effectively, it is of benefit to meet the users' requirements of power quality and power reliability. Moreover, it can reduce the negative impact of the high penetration of renewable energy generation on the distribution network[6-7].

Microgrid has a variety of distributed power types and operating modes so the coordinated control algorithm of distributed power is quite complex[8-9]. Under the premise of guaranteeing the power quality, the mainly technical difficulties for large-scale application of PVstorage microgrid is efficiently taking advantage of each microsource generation, reliably controlling multiple types of microsources in PV-storage microgrid, and effectively meeting the energy balance and output requirements of user[10-12]. In order to solve those problems, this paper has researched the operation of microgrid system network.

The control between micro-grid and distribution grid are the key of safe and stable operation of microgrid. Document [13] put forward a network operation control technique which estimated whether the frequency value and power value met the requirement of disconnection by acquiring frequency and power value from the point of common coupling(PCC). If the value met the disconnecting requirement, the connected point would be cut off. However, this technique did not fully consider the inner condition of microgrid, and it cannot make photovoltaic reach maximum output. Document [14] proposes another control mode. This mode controlled the super capacitor to amend the discharge status of battery through detecting the SOC (State of Charge). It makes use of central control devices, energy control device and load control device to control the energy exchange between utility grid and microgrid and to solve the 
energy exchange problems, but this technique require demanding coordinate control.

Each existing microgrid coordinated control algorithm has its own advantages and disadvantages. However, both of them are difficult to be applied widely. Based on existing micro-grid coordinated research, this paper proposed a multilayer PV-storage micro-grid algorithm with upper scheduling. Having fully considered the multiple operating states of photovoltaic power, this algorithm can achieve maximum output of renewable energy while meeting the distribution scheduling requirements and thus, provided an effective solution for microgrid application.

\section{PV-storage microgrid system designs}

As distributed photovoltaic power generation developing rapidly, the PV-storage microgrid with photovoltaic microsource generation and energy storage system have received attention. In order to achieve power supply reliability, power quality and economical benefit, PVstorage microgrid has a lot of different types of connection and operation. Therefore, when studying the coordinated control algorithms of PV-storage type microgrid, it is necessary to analyze the design of PVstorage type microgrid system.

\subsection{Typical structure of PV-storage microgrid}

The typical topology structure of PV-storage microgrid system is shown in Fig.1. Photovoltaic generators connect to microgrid common bus through a contact line with storage system. When the microgrid system runs in grid-connected mode, photovoltaic generators run under maximum or extreme power output and storage batteries

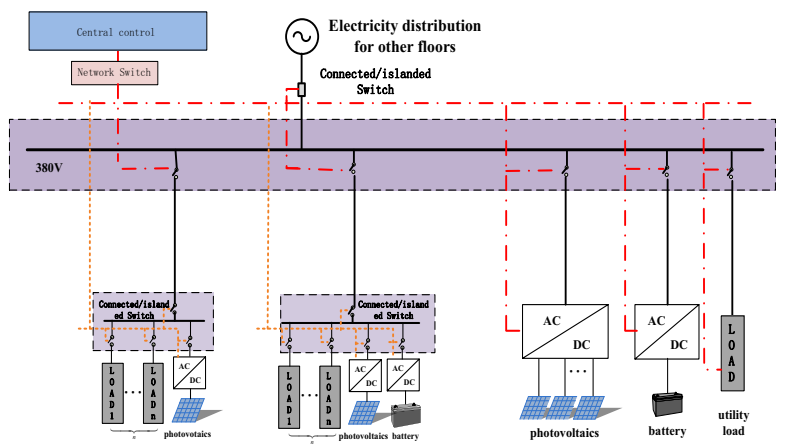

Fig. 1. PV-storage type microgrid schematic diagram

smooth the fluctuations of output power. When an islanding event occurs, microgrid system disconnects form the utility grid and runs in islanded operation mode. Storage batteries work under the V/f control as main power source of the microgrid system to support its voltage and frequency stability. Meanwhile, photovoltaic generators work under maximum or extreme power output to supply power to load in system. These two different operation modes show the flexibility and complexity of microgrid.

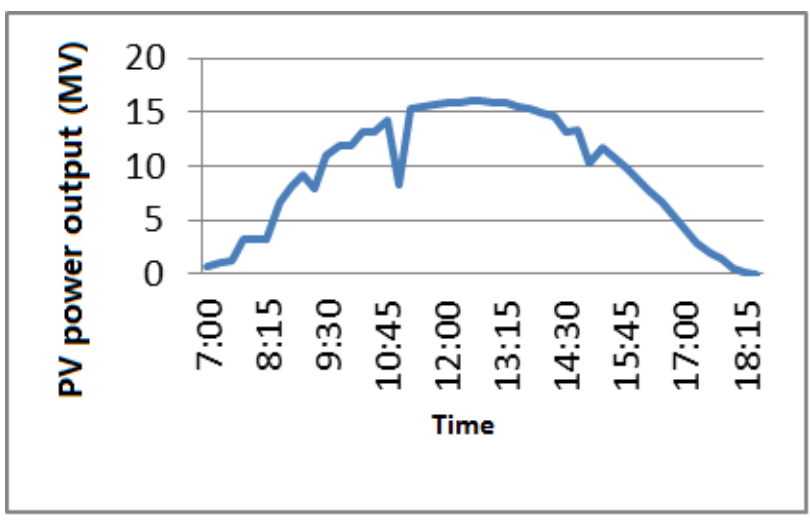

Fig. 2. The characteristic of photovoltaic generation with time changing

\subsection{Microsources function orientation and access principle}

The power supply of PV-storage microgrid includes photovoltaic generation system and storage system. Photovoltaic generator converts solar energy into electrical energy which is the main power source of the PV-storage microgrid besides the utility grid. The output power of photovoltaic generation depends on illumination intensity and temperature. Because illumination intensity and temperature of the day change as the weather conditions and time change, output of photovoltaic generation will show randomness, disturbance, intermittence and other characteristics, as Fig.2 shown.

Therefore, accessing photovoltaic generation should obey the following three principles:

(1) The capacity of photovoltaic generation should not be too large. Photovoltaic generation is the main power supply of microgrid, but it requires complicated control and can only be used during daytime. Accessing excessive capacity will bring negative effect to the utility grid.

(2)Accessing photovoltaic generation requires adjustable power supply for better control of the microgrid.

(3) Photovoltaic generators should always be able to work under maximum power output for effectively control in order to improve stability.

\section{Hierarchical control idea of PV-storage microgrid}

Illumination, temperature and other ambient conditions will greatly influence photovoltaic generation bringing significant vibration and intermittent problems. Energy storage system can change the status of charge and the output power through appropriate control, achieving power complement with photovoltaic generation. However, because of the cost and the limited storage capacity of battery, the storage system can only serve as a short-term energy supplement. Master-slave control, equal control and hierarchical control are three main control methods. For master-slave control, main storage power supply determines the coordinated control of other microsources supply so it requires demanded storage 
reliability. For equal control, photovoltaic generation and energy storage system equally share power shortage to maintain the energy balance and to meet the output requirement. But by using this method, photovoltaic generation cannot always work under extreme power output. Also, this method requires frequent charging and discharging to the storage system, which will shorten the lifespan of the energy storage system. Therefore, multilayer control becomes the mainstream and has engaged on many demonstration engineering projects.

Aiming at satisfying the demand of large-scale application, this paper uses microgrid coordinated control algorithm based on layered structure to divide the control of microgrid into three layers according to different response speed, time scales and communication needs ${ }^{[15]}$, as Fig. 3 shown. The first layer is local control layer. It controls photovoltaic generation, energy storage system and other underlying single device, response and process quickly and does not rely on communication. The second layer is centralized control layer. It maintains voltage and frequency stability of PV-storage microgrid, and keeps the PV-storage type microgrid security and stable. Compared with local control layer, it relies on communication and has a long response time. The third layer is distribution scheduling layer.

It coordinates control between multiple microgrid and dispatches each microgrid output power according to distribution network power requirements and constraints (minimum power loss, lowest economic cost, etc.), which needs several minutes to response and requires high communication reliability[16].

Coordinated control algorithm of centralized control layer is shown in Fig 4. Its main functions include:

(1) Acquiring and processing data from the underlying individual device, monitoring the distributed units and the controllable load.

(2) Achieving short-term and ultra-short-term prediction of photovoltaic generation and loads based on illumination, temperature, historical data and other information.

(3) Acting as "PQ" source when the microgrid operates at grid connected mode and optimizing each power output according to power supply and load forecasting, distribution scheduling.

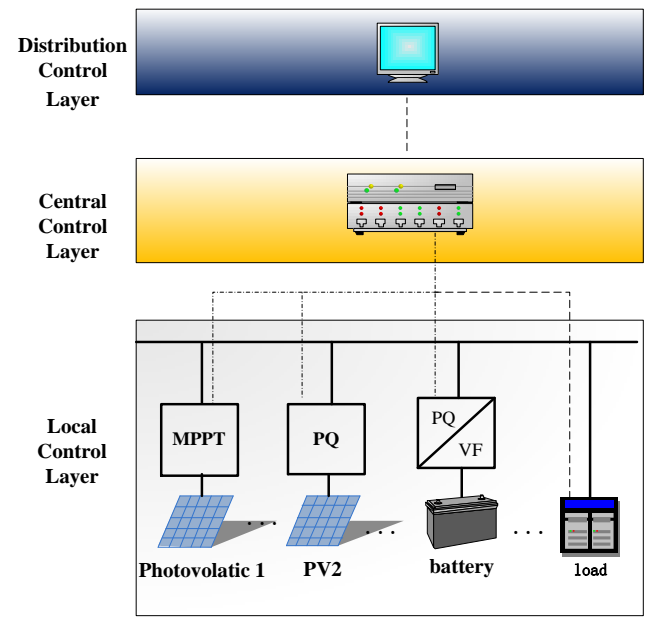

Fig.3. Microgrid coordinated control algorithm

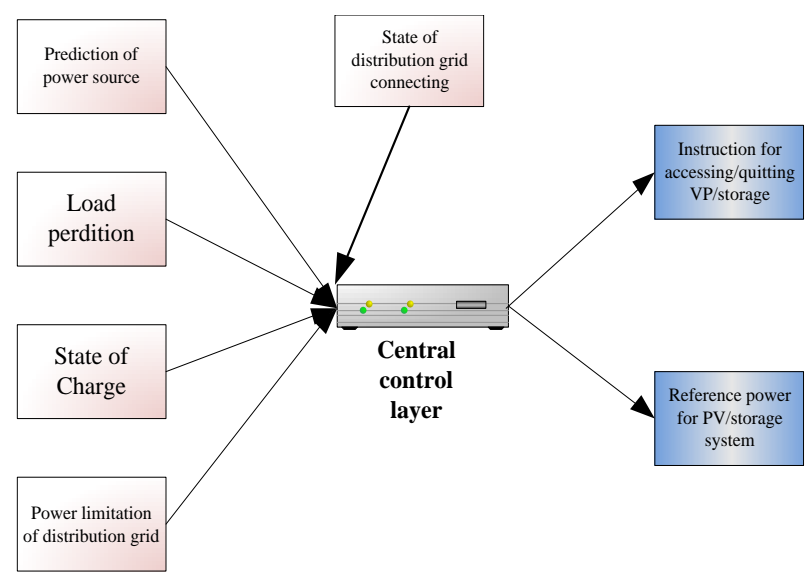

Fig.4. Microgrid Centralized control layer

\section{Grid-connected operation algorithm of PV-storage microgrid}

In grid-connected operation mode, the voltage and frequency of the microgrid are supported by the utility distribution network. The main objective of control algorithms is to maximum the output power of photovoltaic generation and to keep the power in tie line within requirement of distribution network scheduling.

The microgrid working under grid-connected operation mode should satisfy the following constraints:

$$
\left\{\begin{array}{l}
P_{n e t}=\sum P_{p v}+\sum P_{b a t}-\sum P_{\text {load }}-P_{\text {loss }} \\
P_{n e t} \leq P_{d p t} \\
f_{\min } \leq f \leq f_{\max } \\
U_{\min } \leq U \leq U_{\max }
\end{array}\right.
$$

Where:

$P_{n e t}$ is the active power in tie line, threat microgrid transports power to distribution network as positive;

$P_{p v}$ is the active power in photovoltaic generation;

$P_{b a t}$ is the active power in storage system, threat discharge as positive and charge as negative;

$P_{\text {load }}$ is the active power consumed by loads;

$P_{\text {loss }}$ is the internal active power loss in PV-storage microgrid;

$P_{d p t}$ is the active power set by distribution scheduling layer, threat transporting from microgrid to distribution network as positive;

$f_{\max }, f_{\min }$ are upper and lower limitation of frequency;

$U_{\max }, U_{\min }$ are upper and lower limitation of voltage.

Coordinated control algorithm of PV-storage microgrid in grid-connected mode is shown as Fig.5-6. In Fig. 5, $\Delta P=P_{d p t}-P_{n e t}$ is the difference between active power set by distribution scheduling layer and actual active power in tie line, By setting $P_{\text {ofset } 1}$ (positive) and $P_{\text {ofset } 2}$ (negative) reasonably, the algorithm can achieve "hysteresis control" and avoid the fluctuation of 
value of active power in tie line which may lead the control system act frequently. When $\Delta P$ is in hysteresis, the algorithm will then modify the charge and discharge instruction of the central control layer according to the storage charge and discharge power limitation, as shown in the formula (2) :

$$
\left\{\begin{array}{l}
P_{c h i}=\min \left(P_{\text {batChSeto }}, P_{\text {batChLmti }}\right) \\
P_{d h i}=\max \left(P_{\text {batChSet, }}, P_{\text {batDhLmti }}\right)
\end{array}\right.
$$

Where,

$P_{c h i}$ is the corrected charging power of storage system $i$;

$P_{\text {batChSeti }}$ is the charging power of storage system $i$ set by centralized control layer;

$P_{\text {batChLmti }}$ is the charging power limit of storage system $i$, related to SOC state;

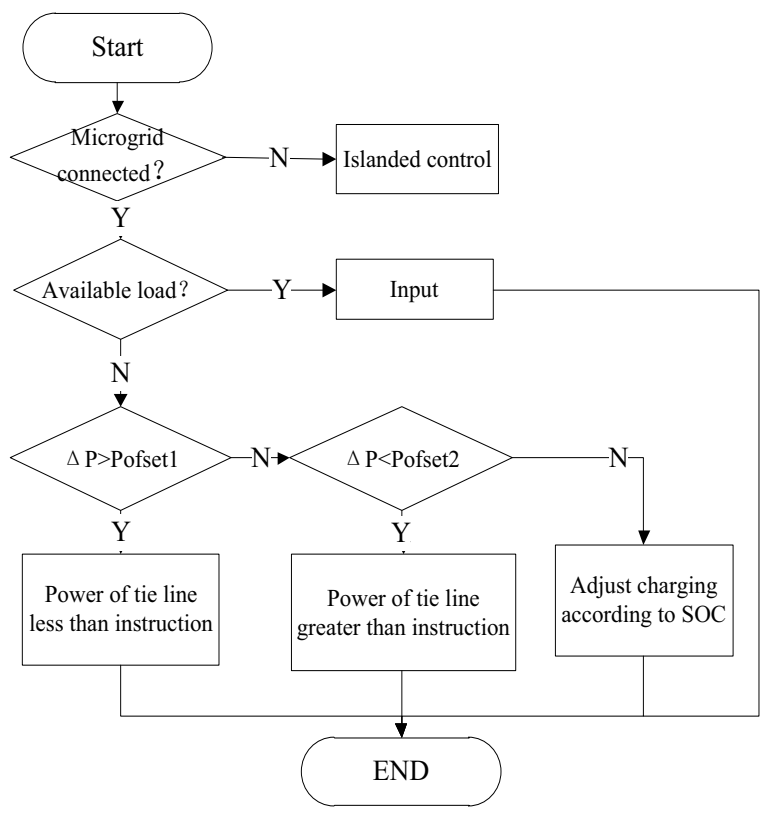

Fig.5. Control algorithm of grid-connected state

$P_{d h i}$ is the corrected discharge power of storage system $i$

$P_{\text {batDhSeti }}$ is the discharge power of storage system $i$ set by centralized control layer;

$P_{\text {batDhLmti }}$ is the storage system $i$ discharge power limit, related to SOC state

Then we are going analyze two modes of coordinated control algorithm when working in grid-connected mode:

\section{A. When tie-line power is less than scheduling instruction}

(1) If energy charging storage exists, reduce energy storage system charging power as following formula:

$$
P_{\text {batChSeti }}=\min \left(0, P_{\text {batRli }}+\Delta P\right)
$$

Where, $P_{\text {batRli }}$ is the actual active power of storage system $i$. This situation generally occurs when the tie line power on the last control period cycle greater than scheduling instruction, and charge the storage system.

(2) If the charging storage cannot meet the requirement, connected photovoltaic generators into the grid, If the photovoltaic system operating mode is MPPT, put photovoltaic power that meet the requirement of the formula (4) into the grid in sequence,

$$
\left\{\begin{array}{l}
P_{m p \operatorname{Pr} j}=\max \left\{P_{m p \operatorname{Pr} i}\right\} \\
P_{m p \operatorname{Pr} i}<\Delta P
\end{array}\right.
$$

Where, $P_{m p \operatorname{Pr} j}$ is the predictive value of the MPPT active power that will be put in;

$j$ is the number of power supply to be put in;

$P_{m p \operatorname{Pr} i}$ is the predictive value of the MPPT active power that can be put in;

If the operating mode of photovoltaic system is $\mathrm{PQ}$ mode, then start all photovoltaic generators and set the PQ output of photovoltaic system according to power distribution principle, as the following formula (5):

$$
P_{p q \operatorname{Seti}}=\min \left(P_{p q \operatorname{Pr} i}, \frac{P_{p q \operatorname{Pr} i}}{\sum P_{p q \operatorname{Pr} i}} \times \Delta P\right)
$$

Where, $P_{p q \text { Seti }}$ is the setting active value of $\mathrm{PQ}$ photovoltaic power to be put in; $P_{p q \mathrm{Pr} i}$ is the predictive active value of $P Q$ photovoltaic power to be put in.

(3) If the whole system was in the condition that the storage system has been charged and the photovoltaic generation system was running on full output power but the system still failed to meet the needs of active distribution scheduling, we can increase the active power output of PQ system as follows:

$$
\left\{\begin{array}{l}
P_{p q A d i}=\min \left(P_{p q R m i}, \frac{P_{p q R m i}}{\sum P_{p q R m i}} \times \Delta P\right) \\
P_{p q R m i}=P_{p q \mathrm{Pr} i}-P_{p q R l i} \\
P_{p q S e t i}=P_{p q R l i}-P_{p q A d i}
\end{array}\right.
$$

Where, $P_{p q A d i}$ is the increasing active power instruction of PV system under PQ operation mode, $P_{p q R l i}$ is the actual active output of PQ photovoltaic system.

(4)If the photovoltaic generation system was fully utilized but still failed to meet the needs of active distribution scheduling, discharged the available energy storage system, its discharging power is set as following formula (7):

$$
P_{\text {batSeti }}=\min \left(P_{\text {batDhLmti }}, P_{\text {batRli }}+\frac{P_{\text {batDhLmti }}-P_{\text {batRli }}}{\sum\left(P_{\text {batDhLmti }}-P_{\text {batRli }}\right)} \times \Delta P\right)
$$




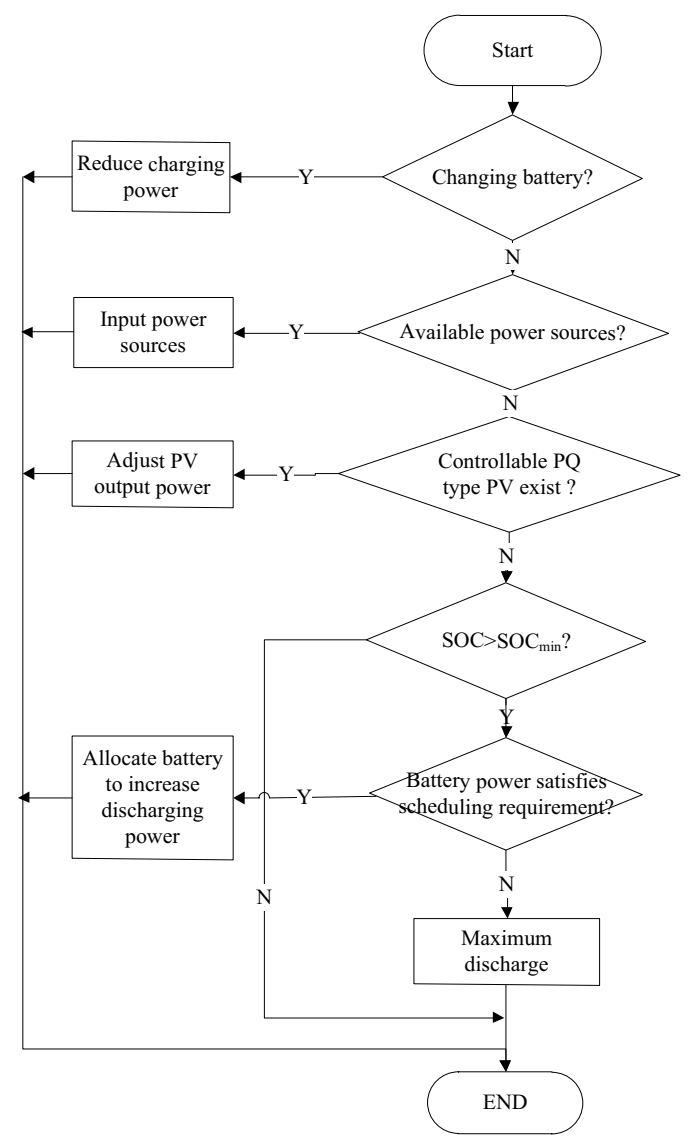

Fig.6. Tie line power is less than scheduling instructions

\section{$B$. When tie-line power is greater than scheduling instruction}

(1) If energy discharging storage exists, reduce energy storage system discharging power as following formula:

$$
P_{\text {batDhSeti }}=\max \left(0, P_{\text {batRli }}+\Delta P\right)
$$

This situation generally occurs when the tie line power on the last control period cycle less than scheduling instruction, and discharge the storage system.

(2)By following the principle of avoiding illumination abandoning control, calculate rechargeable restore power and the sum of PQ active power to determine whether removal MPPT and photovoltaic power operation or not, calculation as follows:

$$
P_{\text {sumCtrl }}=\sum P_{p q R l i}+\sum\left(P_{b a t R l i}-P_{b a t C h L m t i}\right)
$$

(3) Distribution scheduling layer typically want the active output power of PV-storage microgrid to be restricted in scheduling limits. So when removing MPPT photovoltaic systems, remove the nearest value of scheduling active power vacancies, as following formula :

$$
\left\{\begin{array}{l}
k=j,\left|P_{m p R l j}+\Delta P\right|=P_{\min } \\
P_{\min }=\min \left\{\left|P_{m p R l i}+\Delta P\right|\right\}, j=1,2 \ldots n
\end{array}\right.
$$

Where, $P_{m p R l i}$ is active output power of MPPT photovoltaic system needed to be removed. $k$ is the number of MPPT photovoltaic generator nearest to the value of scheduling active power vacancies.
(4) If the whole system was in the condition that the storage system has been discharged and the photovoltaic generation system was cut off but still failed to meet the needs of active distribution scheduling, reduced the active power output of PQ system as following formula (11).

$$
P_{p q \text { Seti }}=P_{p q R l i}+\max \left(-P_{p q R l i}, \frac{P_{p q R l i}}{\sum P_{p q R l i}} \times \Delta P\right)
$$

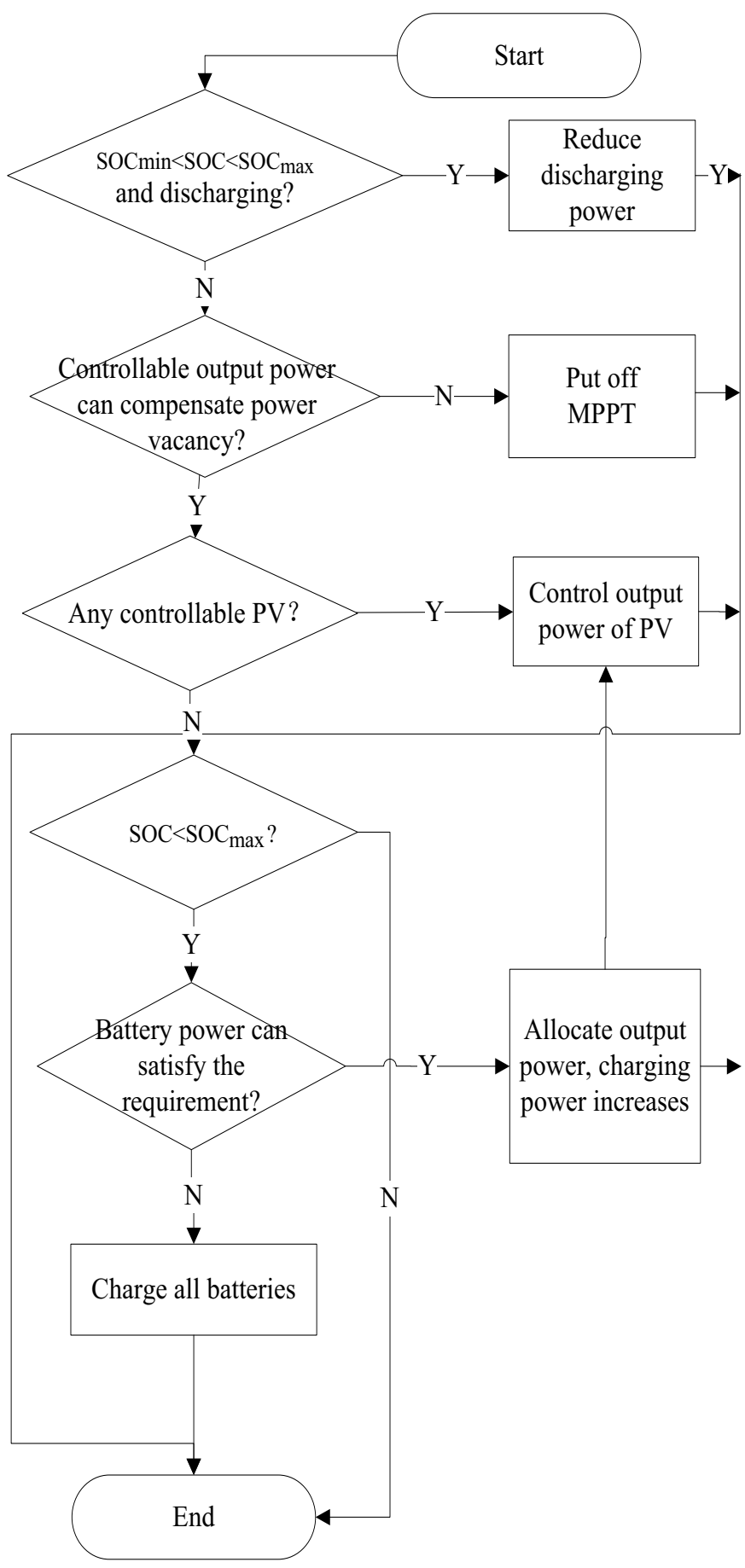

Fig.7. Tie line power is greater than scheduling

(5) If the output power of photovoltaic generation system was reduced but still failed to meet the needs of 
active distribution scheduling, charged the available energy storage system, its charging power was set as following formula.

$$
P_{b a t S e t i}=\max \left(P_{b a t C h L m t i}, \frac{P_{b a t R l i}-P_{b a t C h L m t i}}{\sum\left(P_{b a t R l i}-P_{b a t C h L m t i}\right)} \times \Delta P\right)
$$

\section{Simulation verification}

The test circuit topology of control algorithm of microgrid in grid-connected operation mode is shown in Fig.8. The system consists of photovoltaic, energy storage and load. The photovoltaic system consists of one MPPT type photovoltaic power source whose rated power is $30 \mathrm{~kW}$ and two $\mathrm{PQ}$ type photovoltaic power sources whose rated power is $30 \mathrm{~kW}$. The energy storage system consists of one main battery and one auxiliary battery, the rated power capacity of the main battery is $90 \mathrm{~kW}$, the rated power capacity of the auxiliary battery is $30 \mathrm{~kW}$. There are three static loads whose rated power capacity is $50 \mathrm{~kW}$.

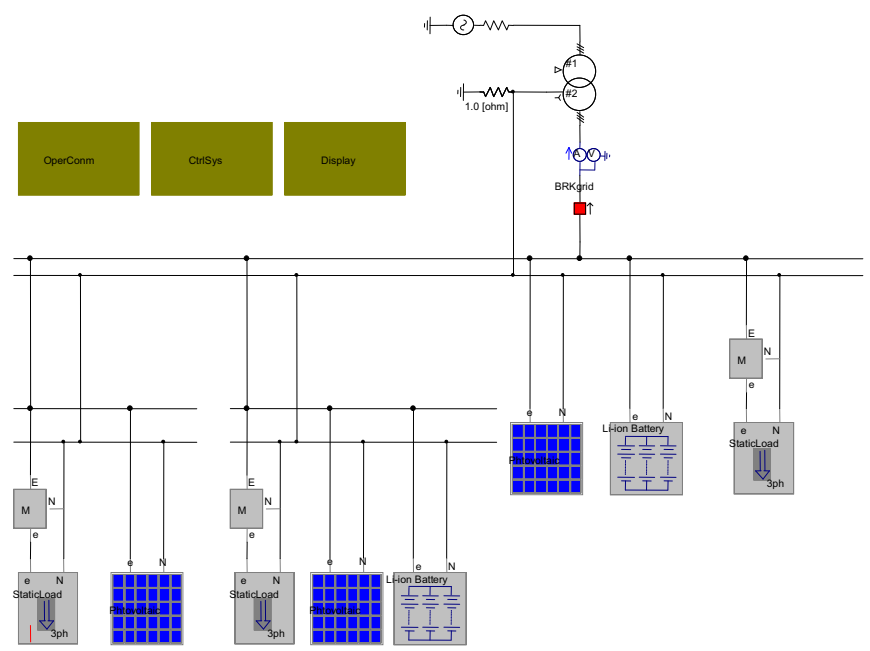

Fig.8. Microgrid Topology

Condition: change both distribution scheduling, illumination and load

Initial condition:

Illumination: $0-5 \mathrm{~s}: 700 \mathrm{~W} / \mathrm{m}^{2}, 5-10 \mathrm{~s}: 900 \mathrm{~W} / \mathrm{m}^{2}$, 10-15s: $1000 \mathrm{~W} / \mathrm{m}^{2}, 15-20 \mathrm{~s}: 600 \mathrm{~W} / \mathrm{m}^{2}, 20-25 \mathrm{~s}$ : $700 \mathrm{~W} / \mathrm{m}^{2}, 25-30 \mathrm{~s}: 900 \mathrm{~W} / \mathrm{m}^{2}, 30-35 \mathrm{~s}: 1000 \mathrm{~W} / \mathrm{m}^{2}$, 35-50s: $600 \mathrm{~W} / \mathrm{m}^{2}$;

Temperature: $25^{\circ} \mathrm{C}$;

Scheduling value: $1-5 \mathrm{~s}: 30 \mathrm{~kW} ; 5-10 \mathrm{~s}: 10 \mathrm{~kW} ; 10-20 \mathrm{~s}$ : -150kW; 20-25s: 30kW; 25-30s: 75kW; 30-35s: 110kW; 35-40s: 75kW; 40-45s: 0kW.

PV 1: type: MPPT, capacity: $30 \mathrm{~kW}$;

PV 2: type: limited power operation, capacity: $30 \mathrm{~kW}$;

PV 3: type: limited power operation, capacity: $30 \mathrm{~kW}$;

Main battery: type: VF, capacity: 90kW, SOC: $65 \%$;

Auxiliary battery: type: PQ, capacity: $30 \mathrm{~kW}$, SOC: $60 \%$;

Load 1: 0-5s: 50kW; 5-10s: 0kW; 10-20s: $15 \mathrm{~kW} ; 20-$ 30s: 50kW; 30-40s: 40kW; 40-45s: 20kW;

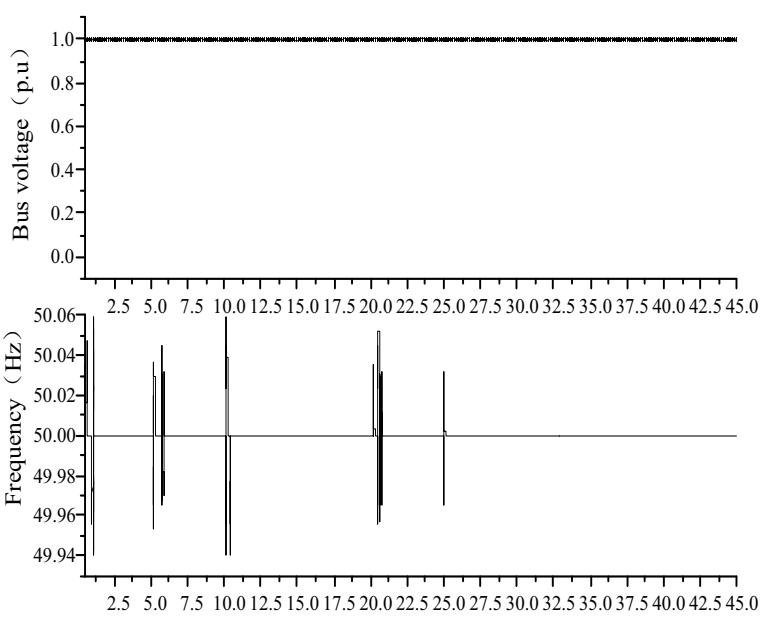

$\mathrm{t}(\mathrm{s})$

(a) Bus bar voltage and frequency change

Load 2: 0-5s: $50 \mathrm{~kW} ; 5-10 \mathrm{~s}: 0 \mathrm{~kW} ; 10-20 \mathrm{~s}: 15 \mathrm{~kW} ; 20-$ 30s: 50kW; 30-40s: 40kW; 40-45s: 20kW;

Load 3: $15 \mathrm{~kW}$ static load;

SOC fixed value: SOCmin1: 10, SOCmin2: 30, SOCmax 2: 80, SOCmax 1: 90;

Simulation time 20 s represents 1 hour.

The initial condition of the system:

Load capacity: $105 \mathrm{~kW}$

PV capacity: 60kW

Power on tie line: $-50 \mathrm{~kW}$.
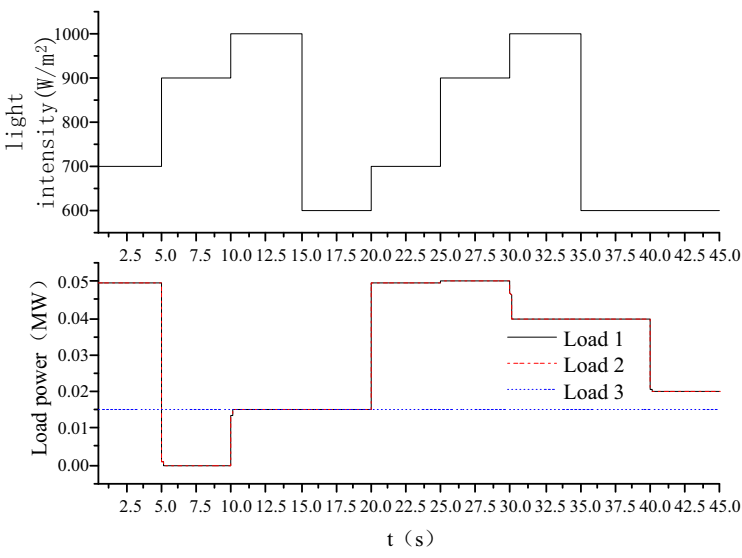

(b) Illumination intensity and load change

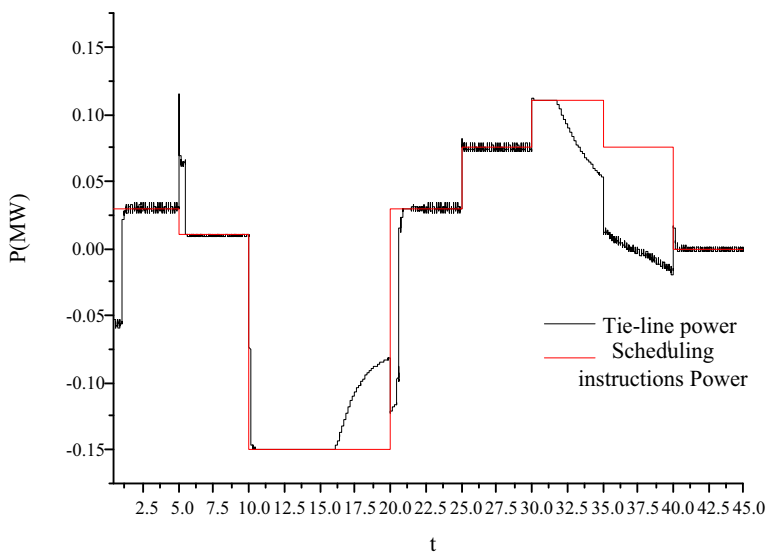

(c) Scheduling instruction and tie line power output comparison 


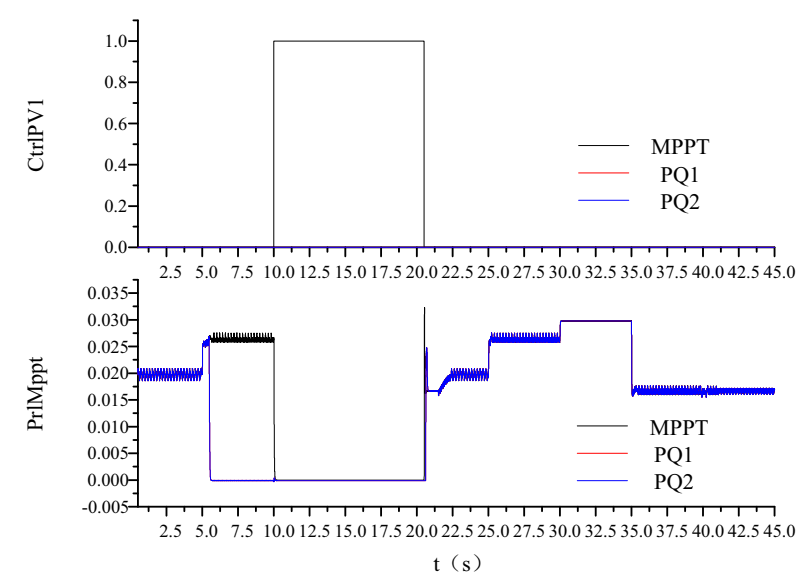

(d) PV control signal and output change

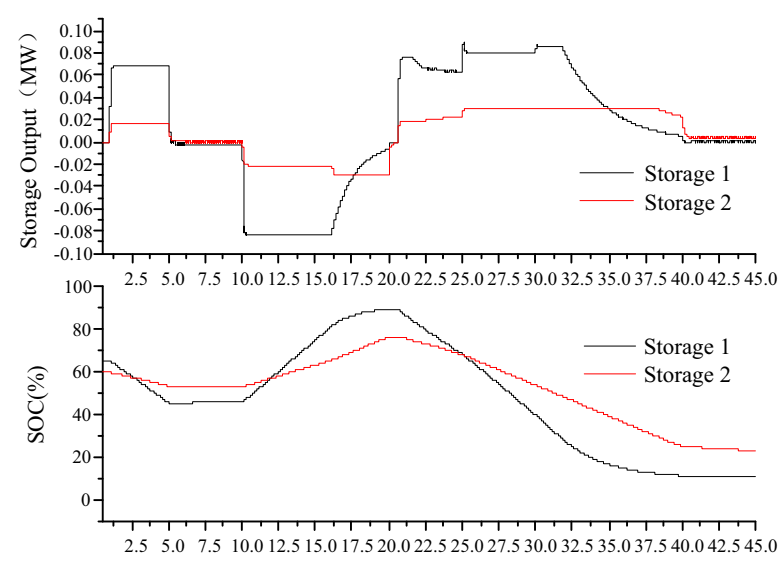

$\mathrm{t}(\mathrm{s})$

(e) Storage output and SOC change

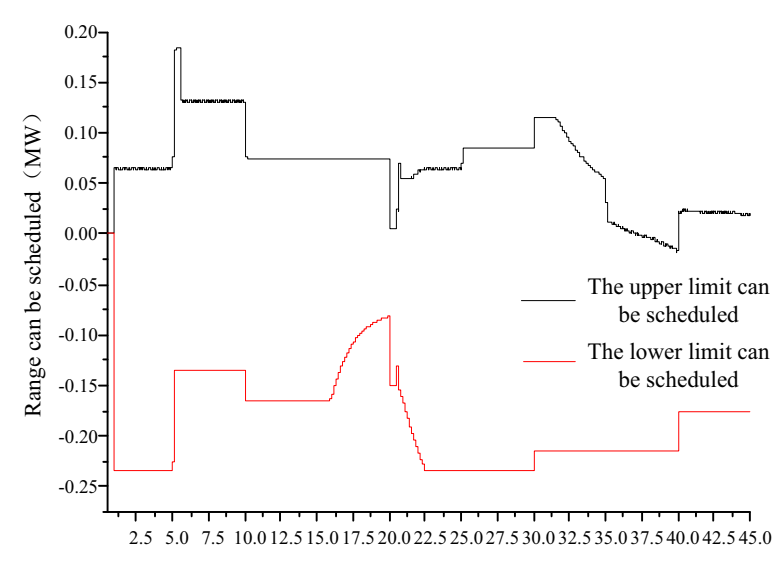

$\mathrm{t}(\mathrm{s})$

(f) Regulating range

Fig.9. Simulation result of state 3

1s later, the distribution scheduling layer sent down instruction of $30 \mathrm{~kW}$. The power of illumination is $700 \mathrm{~W} / \mathrm{m}^{2}$. Under the control of grid-connected algorithm, the two batteries started to discharge, whose discharge power are $69.3 \mathrm{~kW}$ and $16.7 \mathrm{~kW}$. Three photovoltaic power supplies do not work. At this time, the tie line power $P_{n e t}$ is $30 \mathrm{~kW}$, which can follow the scheduling instructions of distribution network and the adjustable power ranges $-235-64 \mathrm{~kW}$.

$5 \mathrm{~s}$ later, the distribution scheduling layer sent down instruction of $10 \mathrm{~kW}$. The power of illumination turns into $900 \mathrm{~W} / \mathrm{m}^{2}$ and the capacity of load turns into $15 \mathrm{~kW}$. The output power of MPPT photovoltaic power supply is $26.35 \mathrm{~kW}$. Under the control of grid-connected algorithm, the two The two storage batteries begin to charge to absorb fluctuation power produced by MPPT photovoltaic power source. At this time, the tie line power $P_{n e t}$ is $10 \mathrm{~kW}$, which can follow the scheduling instructions of distribution network and the adjustable power ranges $-135-131 \mathrm{~kW}$.

10s later the distribution scheduling layer sent down instruction of $-150 \mathrm{~kW}$. The power of illumination turn into $1000 \mathrm{~W} / \mathrm{m}^{2}$ and the capacity of load turn into $15 \mathrm{~kW}$. Under the control of grid-connected algorithm, the MPPT photovoltaic power sources are cut off. The charging power of the two batteries increases to $-83.1 \mathrm{~kW}$ and $21.6 \mathrm{~kW}$. The PQ type photovoltaic power source does not work. At this time, the tie line power $P_{n e t}$ is $-145 \mathrm{~kW}$, which can follow the scheduling instructions of distribution network and the adjustable power ranges $165-74.8 \mathrm{~kW}$.

The simulation results show that under coordinated algorithm control, PV-storage microgrid can operate safely and stably in each condition.

\section{Conclusions}

China has paid great attention on renewable energy and the intelligent grid was developing rapidly. It is of great importance to develop microgrid. The control of PVstorage microgrid is the key of the application of distributed photovoltaic generation as well as the construction of intelligent grid. PV-storage microgrid contains varieties of power sources and complicated working state so that a reliable and efficient way of control is needed to guarantee the safety, stability and economic benefit of the microgrid.

This paper proposes a grid-connected working model of PV-storage microgrid and puts forward a heuristic algorism of multilayer PV-storage microgrid according to the coordinated control of microgrid. This algorism can satisfy the demand of scheduling and enable maximum power output of renewable energy. The results of the simulation show that this algorism enables the microgrid working efficiently and satisfies the requirement of the distributed network dispatches.

\section{Acknowledgments}

This work was supported by the national high technology research and development program (863 Program, 2014AA052001); Guangdong Province science and technology plan project (2012B040303005); Electric Power Research Institute, CSG, science and technology project(SEPRI-K143003); China Southern Power Grid, CSG, science and technology project(K-KY2014-009). 


\section{References}

1. ZHANG Bo-quan, YANG Yi-min, "Status and trend of wind/photovoltaic power development", Electric Power, 2006,06:65-69.

2. GAO Jun-yan, MA Xiu-fan, "Risk Analysis on Influence of Distributed Renewable Power Supply on the Investment Plan of Distribution Network", Power System and Clean Energy, 2008(12):8-12.

3. EI Wei, SHENG Kun, KONG Li, QI Zhi-ping, "Impact and Improvement of Distributed Generation on Distribution Network Voltage Quality", Proceedings of the CSEE, 2008,13:152-157.

4. CHENG Miao-miao, "Optimal Capacity of EnergyStoring Section in PV/Wind Hybrid System", Electrotechnical Application, 2006,06:87-90.

5. Liserre M., Sauter T., Hung J. Y. ,"Future Energy Systems: Integrating Renewable Energy Sources into the Smart Power Grid Through Industrial Electronics ", Industrial Electronics Magazine, IEEE, 2010, 4(1):18-37.

6. Zeng J, Wu J, Liu J F, et al., "An agent-based approach to renewable energy management in ecobuilding", Sustainable Energy Technologies, 2008. ICSET 2008. IEEE International Conference onIEEE, 2008:46-50.

7. Chang J, Jia S Y., "Windy-Solar Power Generation System Based On Multi-Agent System", Machine Learning and Cybernetics, 2008 International Conference on2008:2446 - 2449.
8. XIAO Zhao-xia , "Control and Operation Characteristic Analysis of a MicroGrid", Tianjin University, 2009.

9. "2014 Distributed generation grid-connected innovation development seminar[Z]", EPTC, 2015:2015.

10. R. H. Lasseter, "MicroGrids," in Power Engineering Society Winter Meeting, 2002. IEEE: IEEE, 2002, pp. 305-308 vol.1.

11. N. Hatziargyriou, H. Asano, R. Iravani, and C. Marnay, "Microgrids," IEEE POWER \& ENERGY MAGAZINE, vol. 5, pp. 78-94, 2007.

12. M. Ross, R. Hidalgo, C. Abbey, and G. Joos, "Energy storage system scheduling for an isolated microgrid," IET RENEWABLE POWER GENERATION, vol. 5, pp. 117-123, 2011.

13. PANG Xue-yue, LIAO Yi, ZHANG Xue-yan, "Microgrid grid-connected operation control approach and system[P]", Guangdong, CN103208819A, 2013-07-17.

14. WU Xing, ZHAO Yang-jie, ZHU Yi-xin, "An approach for grid-connected and off-net microgrid and energy control [P]", Shanxi: CN103647274A, 2014-03-19.

15. DING Fei, "Transient Modeling and Simulation of the LV Micro-grid with Multiple Distributed Energy Sources and Energy Storage Elements", Tianjin University, 2010.

16. Adhikari S. Fangxing L., "Coordinated V-f and P-Q Control of Solar Photovoltaic Generators With MPPT and Battery Storage in Microgrids", Smart Grid, IEEE Transactions on, 2014, 5(3):1270-12. 